\title{
Genomic and transcriptomic insights into the thermo-regulated biosynthesis of validamycin in Streptomyces hygroscopicus 5008
}

\author{
Hang $\mathrm{Wu}^{1+}$, Shuang $\mathrm{Qu}^{1 \dagger}$, Chenyang $\mathrm{Lu}^{1}$, Huajun Zheng ${ }^{2}$, Xiufen Zhou', Linquan Bai ${ }^{1 *}$ and Zixin Deng ${ }^{1}$
}

\begin{abstract}
Background: Streptomyces hygroscopicus 5008 has been used for the production of the antifungal validamycin/ jinggangmycin for more than 40 years. A high yield of validamycin is achieved by culturing the strain at $37^{\circ} \mathrm{C}$, rather than at $30^{\circ} \mathrm{C}$ for normal growth and sporulation. The mechanism(s) of its thermo-regulated biosynthesis was largely unknown.

Results: The 10,383,684-bp genome of strain 5008 was completely sequenced and composed of a linear chromosome, a 164.57-kb linear plasmid, and a 73.28-kb circular plasmid. Compared with other Streptomyces genomes, the chromosome of strain 5008 has a smaller core region and shorter terminal inverted repeats, encodes more $\alpha / \beta$ hydrolases, major facilitator superfamily transporters, and $\mathrm{Mg}^{2+} / \mathrm{Mn}^{2+}$-dependent regulatory phosphatases. Transcriptomic analysis revealed that the expression of $7.5 \%$ of coding sequences was increased at $37^{\circ} \mathrm{C}$, including biosynthetic genes for validamycin and other three secondary metabolites. At $37^{\circ} \mathrm{C}$, a glutamate dehydrogenase was transcriptionally up-regulated, and further proved its involvement in validamycin production by gene replacement. Moreover, efficient synthesis and utilization of intracellular glutamate were noticed in strain 5008 at $37^{\circ} \mathrm{C}$, revealing glutamate as the nitrogen source for validamycin biosynthesis. Furthermore, a SARP-family regulatory gene with enhanced transcription at $37^{\circ} \mathrm{C}$ was identified and confirmed to be positively involved in the thermo-regulation of validamycin production by gene inactivation and transcriptional analysis.
\end{abstract}

Conclusions: Strain 5008 seemed to have evolved with specific genomic components to facilitate the thermoregulated validamycin biosynthesis. The data obtained here will facilitate future studies for validamycin yield improvement and industrial bioprocess optimization.

Keywords: Validamycin, Genome, Transcriptome, Streptomyces, Metabolism, Thermo-regulation

\section{Background}

Validamycin A (also named as jinggangmycin A, abbreviated as VAL-A/JIN-A), a basic $\mathrm{C}_{7} \mathrm{~N}$ aminocyclitolcontaining antibiotic, has been widely used as an antifungal agent against rice sheath blight disease in China and other Eastern Asian countries [1]. Meanwhile, its transformed product valienamine is a pharmaceutically important precursor for the synthesis of voglibose, a highly effective drug for insulin-independent diabetes [2]. VAL-A is

\footnotetext{
* Correspondence: bailq@sjtu.edu.cn

${ }^{\dagger}$ Equal contributors

'State Key Laboratory of Microbial Metabolism, and School of Life Sciences \& Biotechnology, Shanghai Jiao Tong University, Shanghai 200030, China
} Full list of author information is available at the end of the article produced at large scale in China by the derivatives of Streptomyces hygroscopicus var. jinggangensis 5008 (hereafter abbreviated as S. hygroscopicus 5008 or strain 5008) for more than 40 years. In other countries including Japan and Korea, VAL-A is produced by S. hygroscopicus var. limoneus [3]. Moreover, a relatively higher fermentation temperature $\left(37^{\circ} \mathrm{C}\right)$ for strain 5008 , rather than $30^{\circ} \mathrm{C}$ for normal Streptomyces growth and sporulation, rendered remarkably increased VAL-A yield, which stands for an unusual example of positive thermo-regulation on antibiotic production $[4,5]$.

Earlier interests and intensive investigation into the primary metabolism, genetic manipulation, bio-catalysis, and biotransformation of the VAL-A producers were

\section{Biomed Central}


greatly stimulated by its agro-medical importance [6-8]. Feeding experiment with isotope-labeled compounds had established that the sedoheptulose 7-phosphate from the pentose phosphate pathway and D-glucose are the precursors for VAL-A biosynthesis $[9,10]$. Furthermore, feeding with a series of ${ }^{15} \mathrm{~N}$-labeled precursors showed that glutamate is the likely primary source of the bridge nitrogen [11,12]. Recently, the complete VAL-A biosynthetic gene clusters were independently cloned from strain 5008, S. hygroscopicus var. yingchengensis 10-22, and S. hygroscopicus var. limoneus [13-16]. Subsequent genetic and biochemical analysis of 10 VAL-A biosynthetic genes confirmed that the sedoheptulose 7phosphate and UDP-glucose are indeed the precursors and cofactors $\mathrm{Co}^{2+}, \mathrm{Mg}^{2+} / \mathrm{Mn}^{2+}, \mathrm{Zn}^{2+}, \mathrm{GTP} / \mathrm{ATP}$, and $\mathrm{NAD}^{+}$are essentially required for VAL-A biosynthesis [17-22]. Moreover, a correlation between enhanced VAL-A productivity and an increased transcription of biosynthetic genes was established in strain 5008 at $37^{\circ} \mathrm{C}$ instead of $30^{\circ} \mathrm{C}[4,5]$. Functional studies of the VAL-A biosynthetic genes at genetic and biochemical levels have also enabled much improved VAL-A productivity, e.g. through feeding proper amount of $\mathrm{Co}^{2+}$, duplicating biosynthetic gene set, or enhancing UDP-glucose biosynthesis [23]. However, the mechanism of the thermoregulation of VAL-A production by strain 5008 remains largely unknown.

To date, the whole genomes of several antibioticproducing actinomycetes have been sequenced, including the avermectin producer $S$. avermitilis, the erythromycin producer Saccharopolyspora erythraea, the streptomycin producer S. griseus, and the rifamycin producer Amycolatopsis mediterranei [24-27]. Since the advent of transcriptomics, proteomics and metabolomics, the genome-based functional studies of antibiotic producers shed new lights on antibiotic biosynthesis, development, regulation, phylogeny and evolution, and mining of the rich repertoire of secondary metabolites [28,29]. In this study, we completely sequenced the genome of S. hygroscopicus
5008 and analyzed its transcriptomes by cultivating the strain at $30^{\circ} \mathrm{C}$ or $37^{\circ} \mathrm{C}$. A Streptomyces Antibiotic Regulatory Protein (SARP)-family regulator was identified to be involved in a positive control of the thermoregulated VAL-A biosynthesis by strain 5008 .

\section{Results}

General features of the S. hygroscopicus $\mathbf{5 0 0 8}$ genome

Except for a linear chromosome, the strain 5008 also harbors a linear plasmid pSHJG1 and a 73,282-bp large circular plasmid (Additional file 1: Figure S1). In order to clone both ends of the linear chromosome and plasmid pSHJG1, we searched for a putative helicase gene homologous to $\operatorname{tr} A$, which is usually located in the termini of actinomycetal chromosomes and linear plasmids [30]. Four putative telomere regions were identified by Southern blotting with $\operatorname{tr} A$ probe, cloned, and sequenced [30]. With a total length of $10,383,684 \mathrm{bp}$, the genome of strain 5008 is larger than most published Streptomyces genomes (Table 1).

The linear chromosome $(10,145,833 \mathrm{bp})$ of strain 5008 , with an average $\mathrm{G}+\mathrm{C} \% \mathrm{~mol}$ content of $71.9 \%$, comprises 8,849 predicted protein-coding sequences (locus tagged as SHJG), 6 rRNA operons (16 S-23 S-5 S), and 68 tRNA genes (Table 1). The replication origin oriC contains at least 18 DnaA box-like sequences [31] and is shifted $875 \mathrm{~kb}$ away from the center to the right (Figure 1A). Intriguingly, it only has 14-bp terminal inverted repeats (TIRs), which is one of the shortest TIRs hitherto found in actinomycetes. Based on a BLASTCLUST analysis, 4,607 (41.6\%) of predicted protein coding sequences (CDSs) are clustered into 924 families.

The linear plasmid pSHJG1 (164,566 bp) (Figure 1B) contains 184 CDSs possibly involved in replication, partitioning, transfer and other biological functions. It lacks a conserved telomere-associated protein (Tap) and TIRs. However, the rightmost $1.2-\mathrm{kb}$ region of pSHJG1 demonstrates a strong homology to the right arm of the chromosome, implying an evolutionary recombination

Table 1 General features of seven completely sequenced Streptomyces chromosomes *

\begin{tabular}{|c|c|c|c|c|c|c|c|c|}
\hline Species & $\begin{array}{l}\text { Length } \\
\text { (bp) }\end{array}$ & $\begin{array}{l}\text { TIR } \\
\text { (bp) }\end{array}$ & $\begin{array}{l}\text { GC Content } \\
(\%)\end{array}$ & $\begin{array}{l}\text { CDS } \\
\text { (no.) }\end{array}$ & $\begin{array}{l}\text { Average CDS } \\
\text { size (bp) }\end{array}$ & $\begin{array}{l}\text { Coding } \\
\text { (\%) }\end{array}$ & $\begin{array}{l}\text { rRNA Operons } \\
\text { (no.) }\end{array}$ & $\begin{array}{l}\text { tRNA } \\
\text { (no.) } \\
\end{array}$ \\
\hline S. hygroscopicus 5008 & $10,145,833$ & 14 & 71.9 & 8,849 & 952 & 83.2 & 6 & 68 \\
\hline S. coelicolor A3(2) & $8,667,507$ & 21,653 & 72.1 & 7,825 & 991 & 88.9 & 6 & 63 \\
\hline S. avermitilis MA-4680 & $9,025,608$ & 49 & 70.7 & 7,582 & 1,027 & 86.3 & 6 & 68 \\
\hline S. griseus IFO13350 & $8,545,929$ & 132,910 & 72.2 & 7,138 & 1,055 & 88.1 & 6 & 66 \\
\hline S. scabies 87.22 & $10,148,695$ & 18,488 & 71.5 & 8,746 & 1,005 & 86.2 & 6 & 75 \\
\hline S. bingchenggensis $\mathrm{BCW}-1$ & $11,936,683$ & 400,000 & 70.8 & 10,023 & 1,031 & 86.6 & 6 & ND \\
\hline S. clavuligerus ATCC 27064 & $6,760,392$ & ND & 72.0 & 5,710 & 1,031 & 87.1 & 6 & 66 \\
\hline
\end{tabular}

* Data were obtained from GenBank: S. coelicolor A3(2), NC_003888; S. avermitilis MA-4680, NC_003155; S. griseus IFO13350, NC_010572; S. scabies 87.22, NC_013929; S. bingchenggensis BCW-1, CP002047; S. clavuligerus ATCC 27064, CM000913. ND, not determined. 


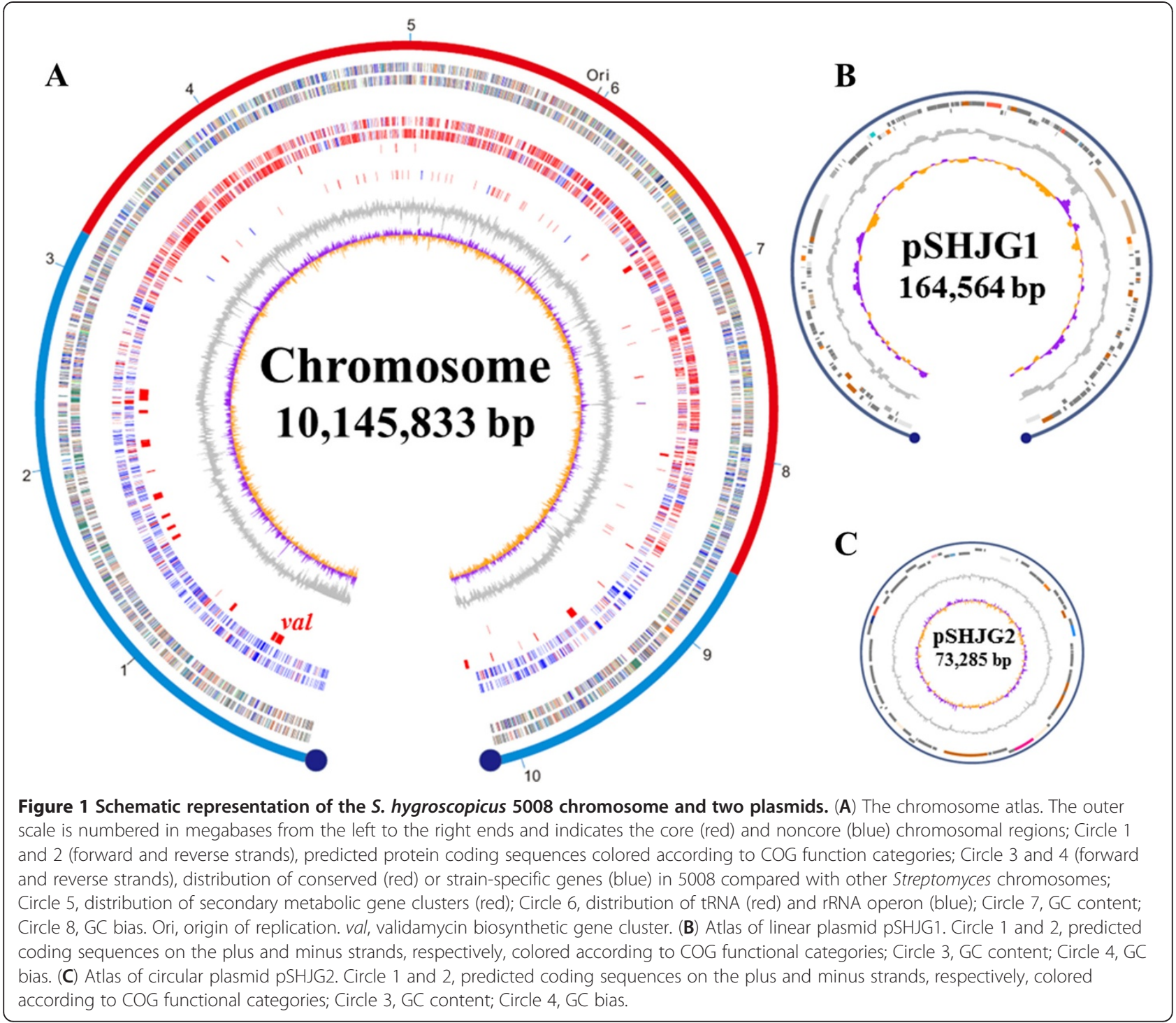

event occurred between the linear plasmid and the chromosome. Moreover, the left terminus of pSHJG1 is equipped with atypical nucleotide sequences consisting of several packed palindromes with non-conserved loop sequences, thereby forming a different secondary structure from its right end and both chromosome ends (Additional file 2: Figure S2). Intriguingly, a complete bacterial immune system CRISPR-Cas [32] was identified in pSHJG1, suggesting a resistance to phages and other invading genetic elements by strain 5008 .

Genome-wide comparison among completely sequenced Streptomyces chromosomes revealed highly conserved core regions ranging from 5.50 to $7.25 \mathrm{Mb}$ [SCLAV0503SCLAV5245 (5.50 Mb), SCO1209-SCO6774 (6.25 Mb), SGR0954-SGR6311 (6.36 Mb), SAV1638-SAV7128 (6.48 Mb), SBI25785-SBI889 (7.12 Mb), SCAB12831SCAB78641 (7.25 Mb)], substantially in proportion to the corresponding chromosomal length. However, the genome of strain 5008 was predicted to have a relatively small core region $(5.56 \mathrm{Mb})$, with a left arm of $3.16 \mathrm{Mb}$ and a right arm of $1.43 \mathrm{Mb}$ (Figure 1A). Syntenic analyses showed that, except for S. scabies, large continuous or separate inversions centered at oriC were detected in the chromosome of strain 5008, when compared with other Streptomyces species (Additional file 3: Figure S3A).

To further identify commonly conserved or speciesspecific proteins in strain 5008, orthologs shared among the seven Streptomyces strains were analyzed by MBGD [33]. The results showed that 2,954 SHJG proteins (33.3\% of the total CDSs), 2,899 SCO proteins (37.3\%), 2,901 SAV proteins (38.3\%), 2,879 SGR proteins (40.3\%), 2,989 SCAB proteins (33.4\%), 2,989 SBI proteins (29.8\%), and 2,806 SCLAV proteins (49.1\%) could be classified into 2,754 clusters (Additional file 3: Figure 
S3B). The major conserved proteins are assigned with functions for transcription, translation, energy production, and amino acid and carbohydrate metabolisms (Additional file 4: Table S1). Notably, 1,640 strainspecific orthologous clusters including 1,749 proteins for strain 5008 could be detected. Surprisingly, the amfABST cluster [34] and the ramR-activated gene (rag) cluster for aerial-mycelium formation and sporulation [35] were not found in strain 5008 (Additional file 5: Table S2).

\section{Gene clusters for secondary metabolites}

Totally 29 gene clusters were identified in the chromosome of strain 5008. Twenty are located in subtelomeric regions with 14 in the left arm and 6 in the right arm. The VAL-A gene cluster ( $\mathrm{val}$ ) is located at a region $350 \mathrm{~kb}$ away from the left end of the chromosome (Figure 1A). Interestingly, the cluster for a peptidyl antibiotic jingsimycin is situated near the right end, which was found to be identical to cyclothiazomycin from S. hygroscopicus var. yingchengensis 10-22 [36] (Additional file 6: Table S3). Among additional 27 gene clusters putatively for secondary metabolites, 6 were assigned for the biosynthesis of polyketides (PKS), 8 for non-ribosomal peptides (NRPS), 5 for hybrid PKSNRPSs, 4 for terpenoids, 1 for lantibiotics, and other 3 for melanin, norcardamine siderophore, and ochronotic pigment (Additional file 6: Table S3), respectively.

\section{Primary metabolism and precursors for validamycin production}

The production of secondary metabolites highly depends on the availability of primary metabolic building blocks [37]. Similar to most Streptomyces, the central carbon metabolism of strain 5008 includes complete glycolysis, the pentose phosphate pathway (PPP), the tricarboxylic acid (TCA) cycle, and gluconeogenesis pathway with multiple copies of genes encoding key enzymes for these pathways (Figure 2, in Additional file 7: Table S4).

VAL-A synthesis requires sedoheptulose 7-phosphate and UDP-glucose derived from carbohydrate metabolism as precursors. The UDP-glucose synthesis is possibly catalyzed by UDP-glucose-1-phosphate uridylyltransferases (Ugp), SHJG4652 and SHJG7333 (sharing 77\% identity), preceded by the isomerization of glucose6-phosphate to glucose-1-phosphate catalyzed by phosphoglucomutase (SHJG1995). Unlike strain 5008, only one copy of ugp gene is present in other sequenced Streptomyces genome, implicating a stronger carbon fluxes from glucose to UDP-glucose for the VAL-A synthesis in strain 5008 (Figure 2). We have recently showed that when a ugp gene (SHJG4652) was overexpressed in an industrial VAL-A producer, increased VAL-A and synchronously decreased validoxylamine A titers were achieved [23].

\section{A vast array of proteins for hydrolysis, transportation, and regulation}

Compared with other six Streptomyces species, strain 5008 has relatively larger proportion of CDSs encoding $\alpha / \beta$ hydrolases (46 vs. 34.4 on average) and MFS transporters (132 vs. 99.3 on average) (Additional file 8: Table S5). There are numerous secreted hydrolases comprising $\alpha / \beta$ hydrolases (46), proteases/peptidases (155), chitinases/chitosanases (9), cellulases/endoglucanases (5), and amylases/pullulanases (6) (Additional file 9: Table S6), suggesting strain 5008 could use a wide range of carbohydrates, including a variety of mono-/oligo-saccharides, chitins, cellulose and starch.

Furthermore, strain 5008 has a complex regulatory network to coordinate the expression of genes involved in metabolism and differentiation, principally including twocomponent systems (TCSs, 53 paired and 28 unpaired), transcriptional regulators (751), sigma (62)/anti-sigma (5)/ anti-anti-sigma (11) factors, and serine/threonine/tyrosine protein kinases (36) (Additional file 9: Table S6). Nevertheless, abundant magnesium or manganese-dependent protein phosphatases (PPMs, 54), including ValP of the VAL-A biosynthetic gene cluster, are clustered in strain 5008 (Additional file 8: Table S5). Some of PPMs are usually involved in sigma $\mathrm{B}\left(\sigma^{\mathrm{B}}\right)$-mediated responds to stress, including heat, osmosis, oxidation responds [38], which agrees well with the VAL-A fermentation process at higher temperature of $37^{\circ} \mathrm{C}$. Whereas each of other Streptomyces strain usually has $1 \gamma$-butyrolactone biosynthetic gene and 1-3 receptor genes [39], strain 5008 contains 3 and 6 homologs of $\gamma$-butyrolactone biosynthetic genes and receptor genes, respectively (Additional file 10: Table S7), signifying a more complicated signaling network in this species.

\section{Transcriptional profiling at different cultivation temperatures}

To explore the molecular mechanism of the positive thermo-regulation on VAL-A biosynthesis, the transcriptomes of strain 5008 cultured at $30^{\circ} \mathrm{C}$ or $37^{\circ} \mathrm{C}$ in liquid medium were compared by microarray analysis. Given more shared orthologs $(4,845)$ between strain 5008 and S. avermitilis NRRL 8165 , we chose $S$. avermitilis cultivated under the same conditions as a filter. Using the statistical criteria of $>2$-fold change and $p<0.05$, a total of 1,542 differentially expressed genes (DEGs) were identified at $37^{\circ} \mathrm{C}$ in strain 5008 (Figure 3A). Likewise, 1,033 genes were differentially transcribed by NRRL8165 under the same cultivation condition (Figure 3A). Filtered with the DNA microarray dataset from NRRL8165, the number of DEGs in 5008 was reduced to 1,405 , and 


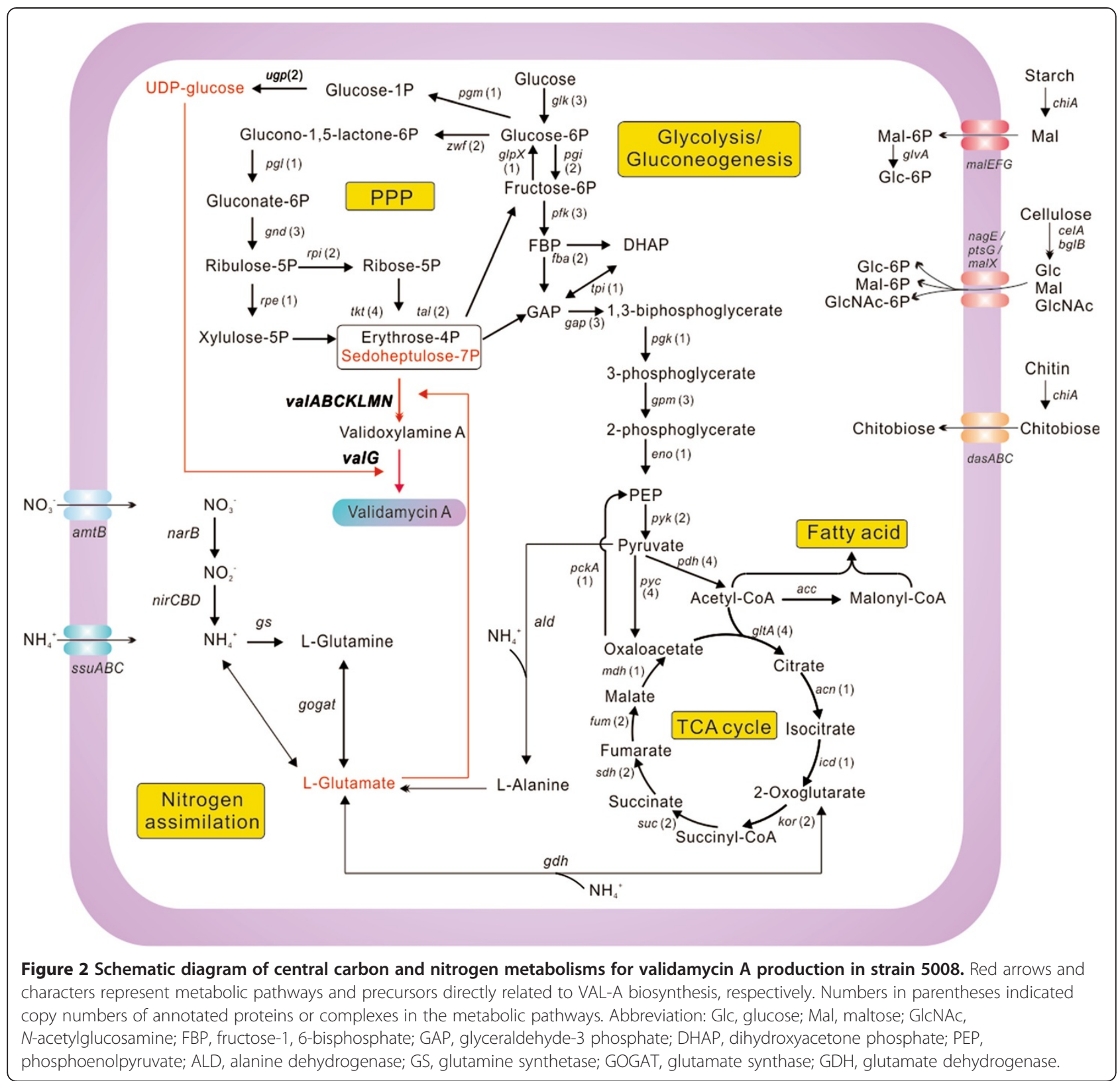

subsequently to 359 using more stringent criteria of $>4$-fold change and $p<0.01$ (Figure 3A).

The markedly down-regulated DEGs at $37^{\circ} \mathrm{C}$ are largely assigned with functions for amino acid transport and metabolism, inorganic ion transport and metabolism, and cell envelope biogenesis (Figure 3B). Consistent with previous observation [5], numerous ribosomal protein genes were moderately up-regulated at $37^{\circ} \mathrm{C}$. As expected, the transcriptional levels of most of the VAL-A biosynthetic genes were markedly enhanced at $37^{\circ} \mathrm{C}$, except for glucosyltransferase gene valG, transporter gene $\mathrm{valH}$, and the two-component regulatory genes valP and valQ. Furthermore, other three gene clusters of PKS-
NPRSs and type-III PKS were also up-regulated by the strain at $37^{\circ} \mathrm{C}$ (Table 2, Additional file 11: Table S8).

Although the genes involved in pentose-phosphate pathway were not dramatically overexpressed at $37^{\circ} \mathrm{C}$, key enzymes for glycolysis were moderately downregulated, including the 6-phosphofructokinase (Pfk), glyceraldehyde-3-phosphate dehydrogenase (Gap), and pyruvate kinase (Pyk). Moreover, gluconokinase (GntK) for phosphorylation of gluconate to generate 6phosphogluconate and citrate lyase ( $\mathrm{CitE}$ ), catalyzing the cleavage of citrate to yield oxaloacetate and acetyl-CoA, had notably enhanced transcription, which could increase the carbon flux to pentose-phosphate pathway 


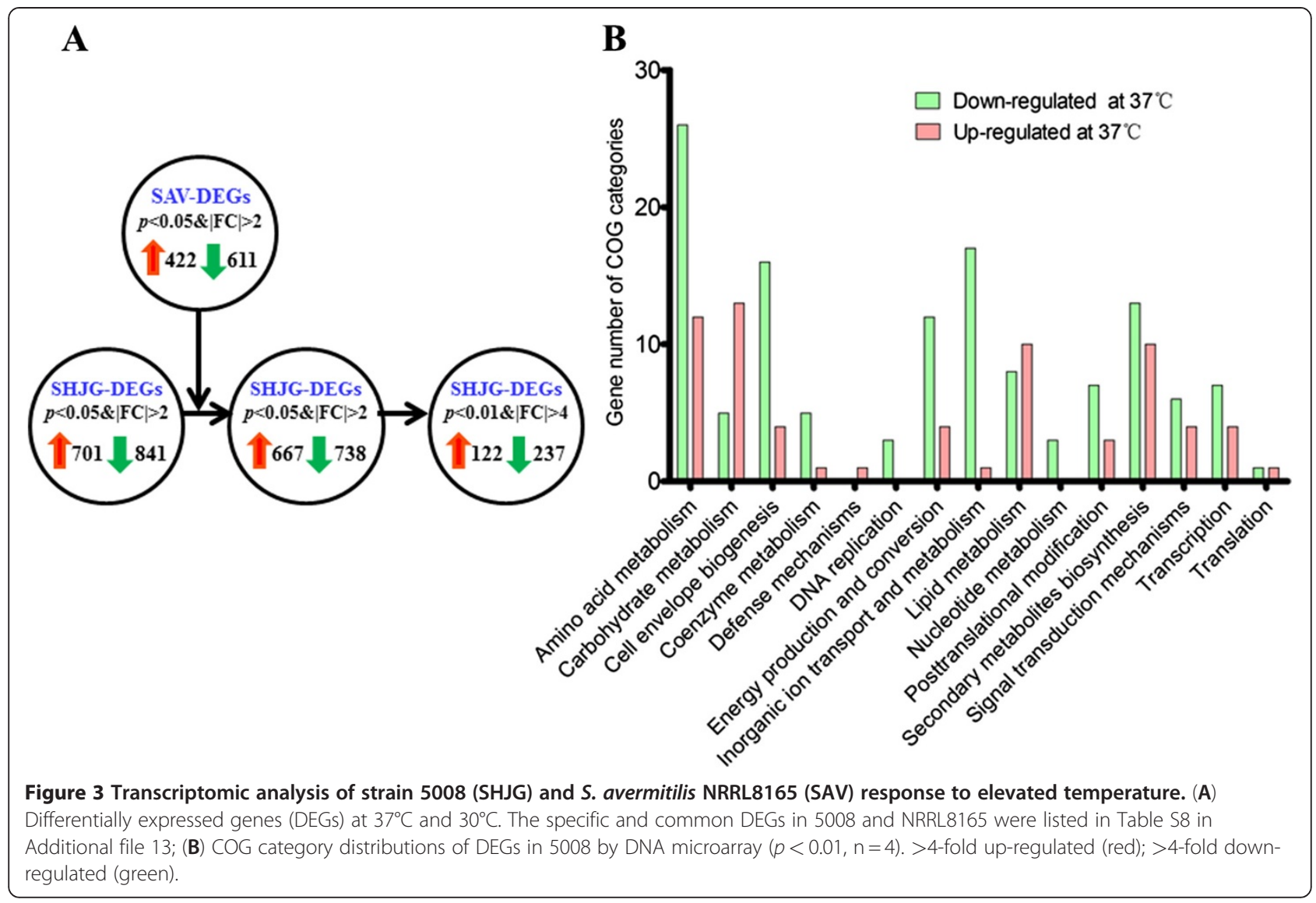

and decrease the TCA cycle (Figure 2, Table 2, Additional file 11: Table S8).

A glutamine synthetase gene $\operatorname{gln} A$ and its positive regulatory gene $g \ln R$ [40] were also down-regulated by strain 5008 at $37^{\circ} \mathrm{C}$, suggesting a low concentration of glutamine and a high concentration of ammonium accumulated in bacterial cells. On the other hand, the gene of glutamate dehydrogenase GdhA (SHJG7666) for converting 2-oxoglutarate into L-glutamate was moderately up-regulated at $37^{\circ} \mathrm{C}$, implying a mechanism for generating more amino group for VAL-A biosynthesis. Accordingly, SHJG7666 was deleted in strain 5008, and a desired mutant JG33 was obtained (Figure 4A-B). HPLC analysis of the extracts from the mutant JG33 displayed obvious reduction of VAL-A production (Figure 4C).

Also, the intracellular concentration of glutamate in strain 5008 and its mutant XH3, with val gene cluster deleted (Additional file 12: Figure S4A, Additional file 13: Method SI), was quantified after 24- and 48-h cultivation using an amino acid analyzer. In 48-h cultured mutant XH3 with validamycin productivity abolished, the intracellular glutamate concentration at $37^{\circ} \mathrm{C}$ $\left(5,123 \mathrm{ng} / \mathrm{mg}\right.$ dry weight) was higher than that at $30^{\circ} \mathrm{C}$ (4,201 ng/mg dry weight), indicating an efficient synthesis of glutamate in S. hygroscopicus 5008 and its derivatives at both temperatures. Moreover, when validamycin was over-produced in strain 5008 at $37^{\circ} \mathrm{C}$ for $48 \mathrm{~h}$, the intracellular glutamate concentration dropped to $1,203 \mathrm{ng} / \mathrm{mg}$ dry weight, less than a fourth of mutant $\mathrm{XH} 3$ and a fifth of strain 5008 cultivated at $30^{\circ} \mathrm{C}$ (6,933 ng/mg dry weight) (Figure 4D). Therefore, the dramatic decrease of intracellular glutamate concentration and the synchronic accumulation of VAL-A in strain 5008 indicated most of the glutamate was consumed for VAL-A biosynthesis at the higher temperature.

\section{A SARP-family regulator involved in the thermo- regulation of VAL-A biosynthesis}

Among the 22 markedly expressed regulators by strain 5008 at $37^{\circ} \mathrm{C}$ (Table 2, in Additional file 11: Table S8), a SARP-family regulatory gene (SHJG0322) was most highly expressed, with a maximum enhancement of 128-fold. SHJG0322 was inactivated by replacing a 610-bp internal sequence with the apramycin resistance gene $a a c(3) I V$ in strain 5008, generating a thiostrepton-sensitive, apramycinresistant $\left(\right.$ Thio $^{\mathrm{S}} \mathrm{Apr}^{\mathrm{R}}$ ) mutant (JG27) (Figure 5A-B).

The wild-type 5008 and the SHJG0322 mutant JG27 were cultivated at $30^{\circ} \mathrm{C}$ or $37^{\circ} \mathrm{C}$ for two days, and the extracts of these cultures were analyzed by HPLC. At $30^{\circ} \mathrm{C}$, the mutant produced $0.07 \mathrm{~g} / \mathrm{L}$ VAL-A, similar to 
Table 2 Selected differentially expressed genes in S. hygroscopicus 5008 at $37^{\circ} \mathrm{C}$ compared with at $30^{\circ} \mathrm{C}$

\begin{tabular}{|c|c|c|}
\hline Description & Gene ID or name & Fold change \\
\hline \multicolumn{3}{|l|}{$\begin{array}{l}\text { Up-regulated genes } \\
\text { at } 37^{\circ} \mathrm{C}\end{array}$} \\
\hline Validamycin biosynthesis & valABCD, valKLMN, valEF, vallJ & 4.1-23.8 \\
\hline PKS-NRPS biosynthesis & SHJG0303-SHJG0325 & $6.8-707.3$ \\
\hline PKS-NRPS biosynthesis & SHJG1907-SHJG1918, SHJG1921-SHJG1929 & $2.1-11.8$ \\
\hline Type III PKS biosynthesis & SHJG8479 & 12.9 \\
\hline Central carbon metabolisms & SHJG3123 (gntK), SHJG3510 (citE) & $4.6-5.2$ \\
\hline Nitrogen metabolism & SHJG7666 (gdhA), SHJG7685 (glnA3) & $2.7-3.0$ \\
\hline Ribosomal proteins & $\begin{array}{l}\text { SHJG0705-SHJG0706, SHJG0835-SHJG0836, SHJG2929, } \\
\text { SHJG5163-SHJG5164, SHJG5778, SHJG5809-SHJG5816 }\end{array}$ & $2.1-3.6$ \\
\hline Heat shock proteins & $\begin{array}{l}\text { SHJG4359 (hspX), SHJG5369-SHJG5372 (dnaK-grpE-dnaJ-hspR), } \\
\text { SHJG7073, SHJG8393 }\end{array}$ & $3.3-5.3$ \\
\hline $\begin{array}{l}\text { Markedly expressed } \\
\text { regulators }\end{array}$ & $\begin{array}{l}\text { SHJG0301, SHJG0319, SHJG0322, SHJG0477, SHJG6588, SHJG6678, } \\
\text { SHJG6961, SHJG7352 }\end{array}$ & $4.3-128.2$ \\
\hline \multicolumn{3}{|l|}{$\begin{array}{l}\text { Down-regulated genes } \\
\text { at } 37^{\circ} \mathrm{C}\end{array}$} \\
\hline Glycolysis & SHJG2653 (pfk), SHJG3403 (gap), SHJG3488 (pyk) & $2.6-3.5$ \\
\hline Nitrogen metabolism & $\begin{array}{l}\text { SHJG2665 (ureD), SHJG2667 (ureE), SHJG2668-SHJG2670 (ureCBA), } \\
\text { SHJG3687 (glnA), SHJG3702 (g/nll), SHJG3730 (glnA2), SHJG3958 (nirB), } \\
\text { SHJG4429 (nark), SHJG4923 (glnR), SHJG6704 (amtB), SHJG6705 (glnB), } \\
\underline{\text { SHJG6706 (glnD) }}\end{array}$ & $4.1-16.7$ \\
\hline $\begin{array}{l}\text { Phosphate starvation } \\
\text { response }\end{array}$ & $\begin{array}{l}\text { SHJG0329 (phoA), SHJG2705, SHJG4290 (ppe), } \\
\text { SHJG4865 (phoU), SHJG4934 (ppk), SHJG4942-SHJG4945 (pstBACS), } \\
\text { SHJG5998-SHJG5999 (neuAB), SHJG8008 (glpQ), SHJG8009 }\end{array}$ & $3.9-144.3$ \\
\hline Sulfate assimilation & $\begin{array}{l}\text { SHJG1828-SHJG1830, SHJG4909 (cysA), SHJG7116, } \\
\text { SHJG7181-SHJG7183 (ssuABC), SHJG7184-SHJG7187 (cysCNDH), } \\
\text { SHJG7188, SHJG7189 (cycl) }\end{array}$ & $4.7-16.8$ \\
\hline Markedly expressed regulators & $\begin{array}{l}\text { SHJG0180, SHJG1204, SHJG1557, SHJG4402, SHJG4865, SHJG5108, } \\
\text { SHJG5332, SHJG6822, SHJG7752, SHJG8626, SHJG8650,SHJG8654, } \\
\text { SHJG8656, SHJG8657 }\end{array}$ & $4.3-31.3$ \\
\hline
\end{tabular}

Differentially expressed genes both in strain 5008 and NRRL 8165 at $37^{\circ} \mathrm{C}$ relative to at $30^{\circ} \mathrm{C}$ are underlined.

the amount produced by the wild-type $5008(0.09 \mathrm{~g} / \mathrm{L})$. At $37^{\circ} \mathrm{C}$, however, the yield of VAL-A in the mutant JG27 was $0.49 \mathrm{~g} / \mathrm{L}$, which was less than $20 \%$ of the widetype productivity $(2.52 \mathrm{~g} / \mathrm{L}$ ) (Figure $5 \mathrm{C}$ ). Detected by quantitative RT-PCR, the relative transcription of VAL -A biosynthetic genes valA and valK of the wild-type 5008 were increased by 100 -fold and 26 -fold at $37^{\circ} \mathrm{C}$ than at $30^{\circ} \mathrm{C}$, respectively (Figure $5 \mathrm{D}$ ). However, the transcription of valA and valK in the mutant JG27 at $37^{\circ}$ $\mathrm{C}$ were both dropped to only 6-fold than at $30^{\circ} \mathrm{C}$ (Figure 5D).

Furthermore, the mutant JG27 was complemented with a cloned SHJG0322 under the control of the PermE* constitutive promoter (pJTU5287) or its native promoter (pJTU5288). A similar amount of VAL-A was produced in both complemented derivatives JG27/ pJTU5287 (2.23 g/L) and JG27/pJTU5288 (2.06 g/L) at $37^{\circ} \mathrm{C}$, which accounted respectively for $88.6 \%$ and $81.6 \%$ of the wild-type yield (Figure $5 \mathrm{C}$ ). At $30^{\circ} \mathrm{C}$, both strains produced comparable amounts of VAL-A to strain 5008 and mutant JG27 (Figure 5C). These results suggested that the SARP gene SHJG0322 was necessary but not adequate for the thermo-regulated validamycin biosynthesis in strain 5008. Probably some other regulatory factors are recruited as well.

\section{Discussion}

Frequently, DNA recombinations including gene duplication, deletion, and acquisition were observed in or near the long-terminal inverted repeats of the linear chromosome ends in Streptomyces [41]. However, the terminal inverted repeats of the chromosome of strain 5008 are $14 \mathrm{bp}$, particularly similar to that of the chromosome of earlier industrial strain $S$. avermitilis [42], suggesting a stable phenotype under higher temperature condition. Unexpectedly, we found the variation in length for the core regions of seven Streptomyces chromosomes from 5.50 to $7.25 \mathrm{Mb}$, apparently different from a previous claim, which was deduced from three chromosomes with similar sizes and certain 


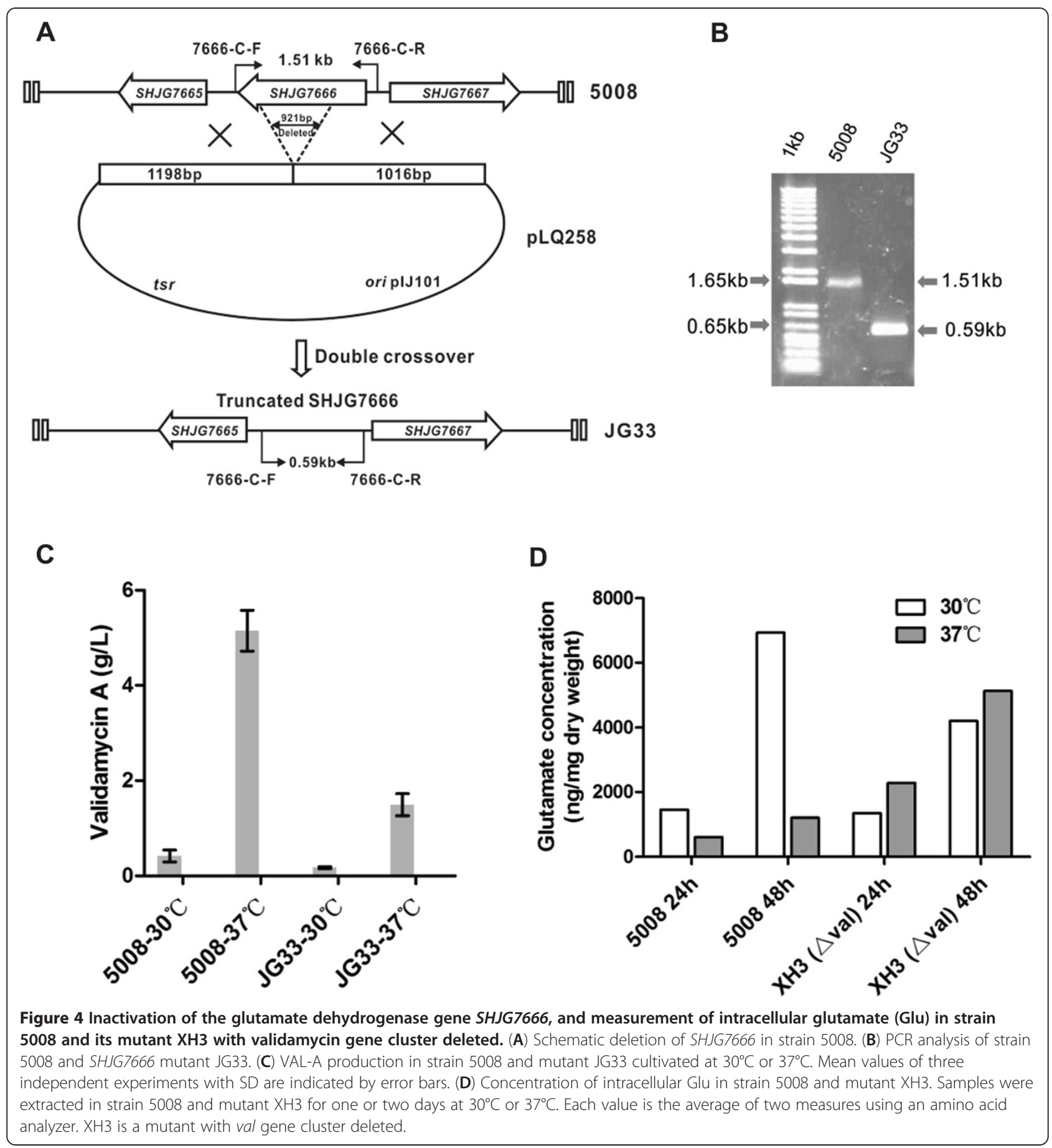

close taxonomical relatedness [26]. Therefore, apart from the chromosome arms, the variation for the core regions could also serve as an auxiliary strategy for Streptomyces genome plasticity, e.g. a major deletion in the central region of $S$. avermitilis was identified [43]. Also, the presence of multiple-copy protein families for central carbon metabolism secures a vigorous and regulable primary metabolism in strain 5008 , which probably provides various precursors for secondary metabolism in different niches.

As revealed by the transcriptome, many genes seemed to be involved in the enhanced VAL-A yield at $37^{\circ} \mathrm{C}$. Besides the significantly enhanced expression of VAL-A biosynthetic genes as previously detected [4], a few key enzymes (Pfk-Gap-Pyk-GntK-CitE) for central carbon metabolism were differentially expressed to redirect 


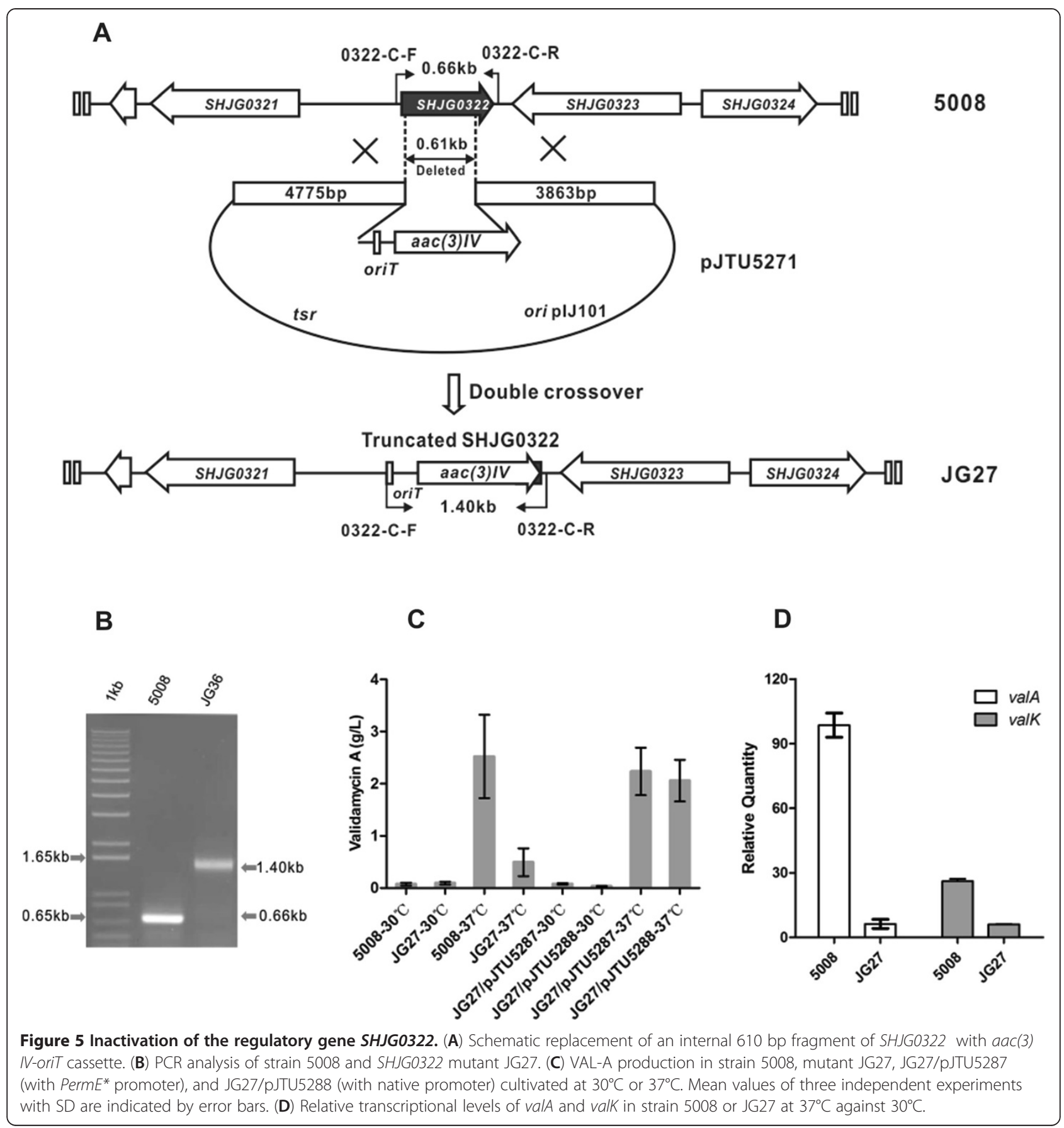

carbon metabolic flux into the pentose phosphate pathway, which generates more carbon precursors for VAL-A production (Figure 2). Moreover, the lower transcripts of most nitrogen assimilation genes and enhanced expression of the glutamate dehydrogenase gene at $37^{\circ} \mathrm{C}$ suggested a condition of high nitrogen supply. Also, when the validamycin gene cluster was deleted, intracellular glutamate concentration at $37^{\circ} \mathrm{C}$ was higher than that at $30^{\circ} \mathrm{C}$ (Figure $4 \mathrm{D}$ ). When validamycin was overproduced at $37^{\circ} \mathrm{C}$ by strain 5008, the intracellular glutamate concentration in the two-day culture was less than a fifth of that at $30^{\circ} \mathrm{C}$ (Figure 4D), indicating that the glutamate was the most probable primary nitrogen source for VAL-A biosynthesis, which agrees well with previous feeding experiments with isotope-labeled precursors $[11,12]$.

Also, the majority of genes involved in nutrient stress responses, especially the phosphate metabolism, displayed lower transcriptional profiles at $37^{\circ} \mathrm{C}$ in strain 5008 (Table 2). It was demonstrated that the production 
of secondary metabolites was generally impeded by excessive inorganic phosphate [44]. Therefore the low expression of phosphate assimilation genes probably results in a low concentration of intracellular inorganic phosphate, which is essential for VAL-A overproduction. Previous reports revealed that these genes for nutrient stress responses are usually mediated by sigma factor $\sigma^{\mathrm{B}}$ or pleiotropic antibiotic regulator AfsS [45,46]. Thus it appears that specific regulatory genes operate in a direct or indirect manner to inhibit the transcription of these genes at $37^{\circ} \mathrm{C}$ in strain 5008 .

At $37^{\circ} \mathrm{C}$, the SARP-family transcriptional regulator SHJG0322 displayed significantly enhanced expression, whose involvement in the thermo-regulation of VAL-A biosynthesis was confirmed through gene inactivation/ complementation and transcriptional analysis (Figure 5). Orthologs of SHJG0322 with bacterial transcriptional activation domain (BTAD) are widely distributed in actinomycetes, including AfsR for global secondary metabolite regulation (identities 42\%) [47], RedD of S. coelicolor for undecylprodigiosin biosynthesis (identities 37\%) [48], etc. However, the 205-aa SHJG0322 is the shortest and the only identified protein related to thermo-regulation so far among its orthologs. It may mediate the interactions with RNA polymerase, other transcription complex proteins, or downstream pathway-specific regulators for the thermo-regulated VAL-A biosynthesis [49]. Furthermore, three up-regulated genes encoding one ECF sigma factor (SHJG4152) and two heat shock proteins (SHJG4359-SHJG8393) at $37^{\circ} \mathrm{C}$ were individually inactivated by homologous recombination in strain 5008 (Additional file 12: Figure S4B-D). Obvious reduction of VAL-A yield was detected in each mutant (Additional file 12: Figure S4E), implying that the SARP gene SHJG0322 might be under the control of sigma factor or heat stress genes. Nevertheless, regulatory mechanism of the SARP gene remains to be further studied. The identification of SHJG0322 would be served as a starting point to investigate the thermo-regulatory cascade for VAL-A biosynthesis.

\section{Conclusions}

In conclusion, the genome of the VAL-A producer $S$. hygroscopicus 5008 was completely sequenced, and the thermo-regulated VAL-A biosynthesis was investigated through transcriptomic analysis, which highlighted unique features for VAL-A production and identified a SARP regulator positively involved in VAL-A biosynthesis. In perspective, the complete genome sequence of $S$. hygroscopicus 5008 will highly facilitate the elucidation of the metabolic and regulatory networks for VAL-A biosynthesis, rational design of high-titer VAL-A producers, and mining of its potentials for secondary metabolism within the context of functional genomics.

\section{Methods}

\section{Genome sequencing and assembly}

S. hygroscopicus var. jinggangensis 5008 genome was sequenced by 454 GS FLX sequencer [50], which resulted in 893,215 reads and provided 17.7-fold coverage. Plasmid library (6-8 kb inserts) and fosmid library (35-45 kb inserts) were respectively constructed with genomic DNA of strain 5008, and end-sequenced to provide contig linkage information. Gaps were filled by primer walking, subcloning, or multiplex PCR. Final sequence assembly of 900,758 reads was done using Phred/Phrap/Consed package, including 893,215 reads from 454 GS FLX, 2,756 from plasmid ends, 3,355 from fosmid ends, and 1,432 specific PCR products and primer walking.

The telomere sequences of the linear chromosome and the linear plasmid pSHJG1 were separately determined as follows. The location of each telomere was identified in the genome using ttrA gene, which encodes a putative helicase and generally exists in the terminal regions of Streptomyces chromosomes or linear plasmids [30]. Each $\operatorname{tr} A$ homologous sequence was amplified and used as probe to localize the corresponding telomere by Southern blotting against genomic DNA, which was digested with appropriate restriction enzymes and separated by agarose gel electrophoresis. Subsequently, the fragments with positive signals were purified from the agarose gel, treated with $0.1-0.2 \mathrm{M} \mathrm{NaOH}$ to remove the terminal proteins, and ligated with pBlueScript II SK digested with a blunt-end enzyme and the same enzyme used for the genomic DNA digestion. The correct recombinant plasmids were verified by restriction digestion and sequencing.

Data of Solexa and Sanger re-sequencing were used to revise the homopolymer error in 454 raw data and the low-quality (phrap score $<40$ ) bases in assembled sequence. Finally, the genome sequence was estimated to have an error rate of $<1 / 10,000$ bases (Phrap score $\geq 40$ ).

\section{Genome annotation and analysis}

Putative protein-coding sequences (CDSs) were predicted using Glimmer 3.02 [51] trained with all annotated CDSs of published complete Streptomyces genomes and Z-Curve [52] software. CDS annotation was based on the BLASTP program with NR, COG, KEGG and CDD databases, followed by manual inspection. The tRNA and transfer-messenger RNA genes were predicted using the tRNAscan-SE [53] and ARAGORN [54] programs, respectively. Pair-wise alignments between the 5008 genome and published Streptomyces genomes were performed using Nucmer or Promer program of the MUMmer package [55]. Proteins were clustered using the BLASTCLUST program under the conditions of a minimum of $30 \%$ identity and $70 \%$ 
length coverage. Ortholog analysis was submitted to the MBGD platform with default parameters [33]. Clustered regularly interspaced short palindromic repeats (CRISPRs) were identified using CRISPR Finder [56].

\section{DNA microarray analysis}

An array of 15,000 specific 60-mer oligonucleotides was designed based on predicted CDSs from S. hygroscopicus 5008 and S. avermitilis NRRL8165, respectively. The oligonucleotides were synthesized and printed onto a glass slide according to the manufacturer's protocol (Agilent).

Strain 5008 or NRRL8165 were pre-cultured at $30^{\circ} \mathrm{C}$ for $48 \mathrm{~h}$ in $50 \mathrm{ml}$ TSB liquid medium plus $1 \%$ yeast extract in $250 \mathrm{ml}$ shaking flasks with reciprocal shaking $(220 \mathrm{rpm}) .0 .5 \mathrm{ml}$ of each culture was inoculated into $50 \mathrm{ml}$ liquid fermentation medium (gram per liter: rice $4.95 \%$, peanut cake $0.9 \%, \mathrm{KH}_{2} \mathrm{PO}_{4} 0.035 \%, \mathrm{NaCl} 0.07 \%$, and $\mathrm{CaCO}_{3}$ 0.03\%, $\mathrm{pH}$ 7.5) in three $250 \mathrm{ml}$ shaking flasks. The batch cultures were incubated at $30^{\circ} \mathrm{C}$ or $37^{\circ} \mathrm{C}$ for $48 \mathrm{~h}(220 \mathrm{rpm})$. Total RNA was isolated using the Trizol reagent according to the manufacturer's instructions (Invitrogen). The RNA was purified by QIAGEN RNeasy Mini Kit, and the quality and quantity was assessed using the Agilent Bioanalyzer 2100 system. $2 \mu \mathrm{g}$ RNA was used to synthesize cDNA, which was further transcribed into cRNA using a transcription mix containing aa-UTP and T7 RNA polymerase. The Cy3labeled cRNA was purified by QIAGEN RNeasy Mini Kit. Hybridization was performed in an Agilent Microarray Hybridization Chamber (Agilent G2545A) for $17 \mathrm{~h}$ at $65^{\circ} \mathrm{C}$. After hybridization, the slides were washed in Gene Expression Wash Buffer (Agilent), and the microarrays were scanned (Agilent G2565BA).

Using Agilent Feature Extraction Software, acquisition and quantification of array images were performed to normalize raw data with Quantile algorithm. Normalized expression ratios were calculated for each gene and tested for significance with the criteria |fold change| $>2.0$ and $p<0.05$. The change value with the lowest $p$ value in a statistical analysis ( $t$ test) was employed as the most reliable one.

To represent the variation in triplicate measurements for each culture condition with one technical replicate, the coefficient of variation (CV) was estimated. Among the four conditions including sixteen samples, at least $98 \%$ of the genome yielded detectable transcripts, and the average coefficient of variation did not exceed 0.15 , as recommended by Agilent for the quality control (Additional file 14: Table S9). Furthermore, these data were verified by qRT-PCR analysis of 8 randomly selected genes in strain 5008. Good consistency was shown between DNA microarrays and qRT-PCR analysis in terms of transcriptional changes (Additional file 15: Table S10), indicating the reliability of the microarray data.

\section{Quantitative RT-PCR analysis}

The transcriptional levels of valA, valK, and 8 selected genes were determined by quantitative RT-PCR. Specific primers were designed using Primer 5.0 as shown in Additional file 16: Table S11. Total RNA was isolated from the mycelia cultured in fermentation medium collected at $48 \mathrm{~h}$ in $30^{\circ} \mathrm{C}$ or $37^{\circ} \mathrm{C}$. The concentration of total RNA treated with DNase I (MBI Fermentas) was measured with Nanodrop (Thermo). Reverse transcription was achieved using cDNA Synthesis Kit (MBI Fermentas). Real-time PCR reactions were performed on the Applied Biosystems 7500 system with Maxima $^{\text {TM }}$ SYBR Green/ROX qPCR Master Mix (MBI Fermentas). The $h r d B$ gene encoding the major sigma factor in Streptomyces was used as the internal control.

\section{Measurement of intracellular free glutamate concentration}

The amino acid analyzer (HITACHI L-8900) was used for the quantification of intracellular free glutamate of two-day cultured strain 5008 or mutant $\mathrm{XH} 3$ with val gene cluster deleted at $30^{\circ} \mathrm{C}$ or $37^{\circ} \mathrm{C}(220 \mathrm{rpm})$ with the ninhydrine colorimetric method. The mycelia were collected from the fermentation medium by centrifugation at

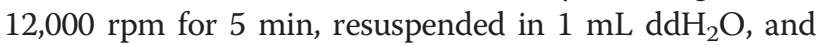
disrupted by sonication in an ice-bath (20 cycles of $5 \mathrm{~s}$ sonication with $10 \mathrm{~s}$ intervals). Cell debris was removed by centrifugation at 12,000 rpm for $5 \mathrm{~min}$. The supernatants were mixed with $10 \%$ salicylsulfonic acid for $20 \mathrm{~min}$ at $-20^{\circ} \mathrm{C}$, and separated by centrifugation at $12,000 \mathrm{rpm}$ for $60 \mathrm{~min}$. Then, the extracts were evaporated, resuspended in $0.02 \mathrm{M} \mathrm{HCl}$, and filtered with a $0.22 \mu \mathrm{m}$ water-phase filter. $20 \mu \mathrm{L}$ of each sample was injected into the amino acid analyzer for glutamate measurement.

\section{Inactivation of the glutamate dehydrogenase gene SHJG7666}

Two segments of 1.20-kb HindIII/EcoRI and 1.01-kb EcoRI/BamHI from strain 5008 were amplified using two primer pairs 7666-L-F/7666-L-R (5'-AATAAGCTTCGA CATCAAGATGCGGATC-3'; 5'-AATGAATTCGGACGT GGTGGTCAACTC-3') and 7666-R-F/7666-R-R (5'-AAT GAATTCCCAGACGAGTGACAGCAA-3'; 5'-AATGGA TCCGCACCGATGTCCTTGAAG-3'), and ligated into HindIII/BamHI-digested pJTU1278 [57], an E. coliStreptomyces shuttle vector, to obtain pLQ258. Then, pLQ258 was introduced into strain 5008 by intergeneric conjugation, and single-crossover exconjugants were screened by thiostrepton resistance $\left(\mathrm{Tsr}^{\mathrm{R}}\right)$. Subsequently, marker-free deletion mutants JG33 were selected from the initial $\mathrm{Tsr}^{\mathrm{R}}$ exconjugants after several rounds of nonselective growth, and confirmed by PCR amplification using the primer pairs 7666-C-F (5'-TCGTGGAGAAGTGGTACA$\left.3^{\prime}\right)$ and 7666-C-R (5'-GCCGCTACTGACTAACTG-3'). 


\section{Inactivation and complementation of the SARP-family regulatory gene SHJG0322}

Using Redirect Technology [58], SHJG0322 in wild-type strain 5008 was replaced by a cassette containing an apramycin-resistant marker $a a c(3) I V$ and the origin of transfer oriT as described below. The oligonucleotides 0322-T-F (5'-CGGGACAAACTCCCCGGTGCTCCGGA CAACGCGCTCCAGGCCATCATTCCGGGGATCCGT CGACC-3') and 0322-T-R (5'-GGCGCCGTCATGTC GCGCACGGCCGGTTCACCGGGCGAGCGCGGTTG TAGGCTGGAGCTGCTTC-3') were used as the forward and reverse primers with the plasmid pIJ773 homologous sequences underlined. The aac(3)IV-oriT cassette was amplified with pIJ773 as a template by PCR and electroporated into E. coli BW25113/pKD46/Fosmid13B1, generating a recombinant fosmid pJTU5270. Then, a 9.2-kb KpnI fragment containing the mutated SHJG0322 from pJTU5270 was cloned into pJTU1278 [57] to give pJTU5271. The plasmid pJTU5271 was introduced into the strain 5008 by intergeneric conjugation as described [13]. Exconjugants with double crossovers were screened for their thiostrepton sensitivity and apramycin resistance, and total DNA was isolated and further confirmed using PCR with primers 0322-C-F (5'TCCGGACAACGCGCTCCAGGCCATC-3') and 0322C-R (5'-GGCCGGTTCACCGGGCGAGCGCGGT-3').

Also, the mutant JG27 was complemented with cloned SHJG0322. Firstly, a 618-bp SHJG0322 was amplified using the primers 0322-A-F (5'-AATCATATGG TGGCACGGGTCCGCAAGGTACT-3') and 0322-A-R (5'-AATGAATTCTCACCGGGCGAGCGCGGTCACGG $\left.-3^{\prime}\right)$, cleaved with NdeI and EcoRI, and cloned into pJTU968 to obtain pJTU5286. Then, the fragment containing PermE* and SHJG0322 was cleaved by MunI and EcoRI digestion of pJTU5286, and cloned into the integrative vector pPM927 to generate pJTU5287. Alternatively, a 1.3-kb fragment including the 618-bp SHJG0322 and its 706-bp upstream sequence, probably containing the native promoter, was amplified by PCR using the primers 0322B-F (5'-AATGAATTCGGCGGTCGGCGGACACATGCGG G-3') and 0322-B-R (5'-AATGAATTCTCACCGGGCGAG CGCGGTCACGG-3'), with the engineered EcoRI sites underlined. The 1.3-kb EcoRI-digested fragment was cloned into EcoRI-digested pPM927 to generate pJTU5288. Subsequently, pJTU5287 and pJTU5288 were introduced from E. coli into JG27 through conjugation, and exconjugants were selected with thiostrepton as previously described [23].

Constructions of other knock-out mutants of strain 5008 in this study are described in Additional file 13: Method SI.

\section{Analysis of validamycin A production}

VAL-A production by the wide-type strain 5008 and its derivatives were detected using high performance liquid chromatography (HPLC) analysis. The strains were cultured with $50 \mathrm{~mL}$ fermentation medium in $250 \mathrm{~mL}$ baffled flasks at $30^{\circ} \mathrm{C}$ or $37^{\circ} \mathrm{C}$ for two days $(220 \mathrm{rpm})$. Fermentation broths were centrifuged at 12,000 rpm for $1 \mathrm{~min}$ followed by purification of the supernatant with water-phase filters. The extracted supernatants were directly loaded onto a ZORBAX-SB-C18 column for HPLC analysis [13].

\section{Accession numbers}

The genome sequences have been deposited at NCBI under the accession numbers [GenBank: CP003275], [GenBank: CP003276] and [GenBank: CP003277]. Details of the microarray design, transcriptome experimental design, and transcriptome data have been deposited in the NCBI Gene Expression Omnibus under accession numbers [GEO: GSE35610] and [GEO: GSE35611].

\section{Additional files}

Additional file 1: Figure S1. Confirmation of the two plasmids from
S. hygroscopicus 5008.

Additional file 2: Figure S2. Telomeres of S. hygroscopicus 5008.

Additional file 3: Figure S3. Comparative analyses of the chromosomes of S. hygroscopicus 5008 with that of other six Streptomyces species.

Additional file 4: Table S1. COG categories of conserved and specific proteins in the seven Streptomyces chromosomes.

Additional file 5: Table S2. Selected genes for aerial mycelium and spore formation in S. hygroscopicus 5008 and other sequenced Streptomyces genomes.

Additional file 6: Table S3. Putative gene or gene clusters for secondary metabolites in S. hygroscopicus 5008.

Additional file 7: Table S4. Central carbon metabolic pathways and corresponding gene copy numbers in S. hygroscopicus 5008.

Additional file 8: Table S5. Protein families in S. hygroscopicus 5008 and other six Streptomyces chromosomes completed.

Additional file 9: Table S6. Selected genes encoding hydrolases, and regulators as mentioned in the main text.

Additional file 10: Table S7. Alignment between ArpA/AfsA from S. griseus and S. hygroscopicus 5008 genome with BLASTP program (e value $=1 \mathrm{e}-10$ )

Additional file 11: Table S8. Detailed transcriptomic analysis in S. hygroscopicus 5008 and S. avermitilis NRRL8165.

Additional file 12: Figure S4. Constructions of other knock-out mutants of S. hygroscopicus 5008

Additional file 13: Method SI. Constructions of other knock-out mutants of S. hygroscopicus 5008 described in this study.

Additional file 14: Table S9. Quality-control parameters of DNA microarray data set in S. hygroscopicus 5008 and S. avermitilis NRRL8165.

Additional file 15: Table S10. Quantitative RT-PCR analysis of selected genes in S. hygroscopicus 5008.

Additional file 16: Table S11. Sequences of primer pairs for qRT-PCR assay.

\section{Abbreviations}

ABC: ATP-binding cassette; CDSs: Protein coding sequences;

DEGs: Differentially expressed genes; MFS: Major facilitator superfamily; NRPS: Non-ribosomal peptide synthetase; PKS: Polyketide synthase; PPMs: Magnesium or manganese-dependent protein phosphatases; PPP: Pentose phosphate pathway; PTS: Phosphotransferase systems; qRTPCR: Quantitative real-time polymerase chain reaction; SARP: Streptomyces 
antibiotic regulatory protein; TCA: Tricarboxylic acid; TCS: Two-component systems.

\section{Competing interests}

The authors declare that they have no competing interests.

\section{Acknowledgements}

We are grateful to Yun Fan, Prof. Zhongjun Qin, and Prof. Chengshu Wang of the Institute of Plant Physiology and Ecology, Chinese Academy of Sciences, for the help on the cloning of the ends of linear replicons and valuable suggestions. We thank Prof. Hongyu Ou for the help on genome analysis. This work received financial supports from the Ministry of Science and Technology (2009CB118901, 2012CB721005) and the National Natural Science Foundation of China (31070070).

\section{Author details}

'State Key Laboratory of Microbial Metabolism, and School of Life Sciences \& Biotechnology, Shanghai Jiao Tong University, Shanghai 200030, China. ${ }^{2}$ Shanghai-MOST Key Laboratory of Disease and Health Genomics, Chinese National Human Genome Center at Shanghai, Shanghai 201203, China.

\section{Authors' contributions}

LQB and HW conceived and designed the experiments. HW and HJZ were responsible for sequencing, finishing and annotation. HW, SQ and LQB performed and contributed to the microarray data processing and analysis. SQ, CYL, HW and LQB carried out the experiments and data analysis. HW, LQB and ZXD were involved in drafting the manuscript. All authors read and approved the final manuscript.

Received: 21 March 2012 Accepted: 24 July 2012

Published: 24 July 2012

\section{References}

1. Iwasa T, Higashide E, Shibata M: Studies of validamycins, new antibiotics. 3. Bioassay methods for the determination of validamycin. J Antibiot (Tokyo) 1971, 24(2):114-118.

2. Matsumoto K, Yano M, Miyake S, Ueki Y, Yamaguchi Y, Akazawa S, Tominaga Y: Effects of voglibose on glycemic excursions, insulin secretion, and insulin sensitivity in non-insulin-treated NIDDM patients. Diabetes Care 1998, 21(2):256-260.

3. Iwasa T, Yamamoto H, Shibata M: Studies on validamycins, new antibiotics. I. Streptomyces hygroscopicus var. limoneus nov. var., validamycin-producing organism. J Antibiot (Tokyo) 1970, 23(12):595-602.

4. Li L, Bai L, Zhou X, Deng Z: Enhanced validamycin production and gene expression at elevated temperature in Streptomyces hygroscopicus subsp. jinggangensis 5008. Chin Sci Bull 2009, 54(7):1204-1209.

5. Liao Y, Wei ZH, Bai L, Deng Z, Zhong JJ: Effect of fermentation temperature on validamycin A production by Streptomyces hygroscopicus 5008. J Biotechnol 2009, 142(3-4):271-274.

6. Xia TH, Jiao RS: Studies on glutamine synthetase from Streptomyces hygroscopicus var. jinggangensis. Sci Sin B 1986, 29(4):379-388.

7. Asano N, Takeuchi M, Ninomiya K, Kameda Y, Matsui K: Microbial degradation of validamycin A by Flavobacterium saccharophilum. Enzymatic cleavage of C-N linkage in validoxylamine A. J Antibiot (Tokyo) 1984, 37(8):859-867.

8. Xue YP, Zheng YG, Shen YC: Preparation of trehalase inhibitor validoxylamine $\mathrm{A}$ by biocatalyzed hydrolysis of validamycin $\mathrm{A}$ with honeybee (Apis cerana Fabr.) beta-glucosidase. Appl Biochem Biotechnol 2005, 127(3):157-171.

9. Degwert U, van Hulst R, Pape H, Herrold RE, Beale JM, Keller PJ, Lee JP, Floss $\mathrm{HG}$ : Studies on the biosynthesis of the alpha-glucosidase inhibitor acarbose: valienamine, a $\mathrm{m}-\mathrm{C}_{7} \mathrm{~N}$ unit not derived from the shikimate pathway. J Antibiot (Tokyo) 1987, 40(6):855-861.

10. Toyokuni $T$, Jin $W$, Rinehart KL: Biosynthetic studies on validamycins: a $\mathrm{C} 2+\mathrm{C} 2+\mathrm{C} 3$ pathway to an aliphatic C7N unit. J Am Chem Soc 1987, 109(11):3481-3482.

11. Mahmud T, Lee S, Floss HG: The biosynthesis of acarbose and validamycin. Chem Rec 2001, 1(4):300-310

12. Lee S, Egelkrout E: Biosynthetic studies on the alpha-glucosidase inhibitor acarbose in Actinoplanes sp.: glutamate is the primary source of the nitrogen in acarbose. J Antibiot (Tokyo) 1998, 51(2):225-227.
13. Yu Y, Bai L, Minagawa K, Jian X, Li L, Li J, Chen S, Cao E, Mahmud T, Floss $\mathrm{HG}$, et al: Gene cluster responsible for validamycin biosynthesis in Streptomyces hygroscopicus subsp. jinggangensis 5008. Appl Environ Microbiol 2005, 71(9):5066-5076.

14. Bai L, Li L, Xu H, Minagawa K, Yu Y, Zhang Y, Zhou X, Floss HG, Mahmud T, Deng Z: Functional analysis of the validamycin biosynthetic gene cluster and engineered production of validoxylamine A. Chem Biol 2006, 13(4):387-397.

15. Jian $X$, Pang $X, Y u$ Y, Zhou $X$, Deng Z: Identification of genes necessary for jinggangmycin biosynthesis from Streptomyces hygroscopicus 10-22. Antonie Van Leeuwenhoek 2006, 90(1):29-39.

16. Singh D, Seo MJ, Kwon HJ, Rajkarnikar A, Kim KR, Kim SO, Suh JW: Genetic localization and heterologous expression of validamycin biosynthetic gene cluster isolated from Streptomyces hygroscopicus var. limoneus KCCM 11405 (IFO 12704). Gene 2006, 376(1):13-23.

17. Minagawa $K$, Zhang Y, Ito T, Bai L, Deng Z, Mahmud T: ValC, a new type of $C_{7}$-Cyclitol kinase involved in the biosynthesis of the antifungal agent validamycin A. ChemBioChem 2007, 8(6):632-641.

18. Xu H, Yang J, Bai L, Deng Z, Mahmud T: Genetically engineered production of 1,1'-bis-valienamine and validienamycin in Streptomyces hygroscopicus and their conversion to valienamine. App/ Microbiol Biotechnol 2009, 81(5):895-902.

19. Xu H, Zhang Y, Yang J, Mahmud T, Bai L, Deng Z: Alternative epimerization in $\mathrm{C}_{7} \mathrm{~N}$-aminocyclitol biosynthesis is catalyzed by ValD, a large protein of the vicinal oxygen chelate superfamily. Chem Biol 2009, 16(5):567-576.

20. Xu H, Minagawa K, Bai L, Deng Z, Mahmud T: Catalytic analysis of the validamycin glycosyltransferase (ValG) and enzymatic production of 4"-epi-validamycin A. J Nat Prod 2008, 71(7):1233-1236.

21. Yang J, Xu H, Zhang Y, Bai L, Deng Z, Mahmud T: Nucleotidylation of unsaturated carbasugar in validamycin biosynthesis. Org Biomol Chem 2011, 9(2):438-449.

22. Asamizu S, Yang J, Almabruk KH, Mahmud T: Pseudoglycosyltransferase catalyzes nonglycosidic C-N coupling in validamycin A biosynthesis. J Am Chem Soc 2011, 133(31):12124-12135.

23. Zhou X, Wu H, Li Z, Bai L, Deng Z: Over-expression of UDP-glucose pyrophosphorylase increases validamycin $A$ but decreases validoxylamine A production in Streptomyces hygroscopicus var. jinggangensis 5008. Metab Eng 2011, 13(6):768-776.

24. Ikeda H, Ishikawa J, Hanamoto A, Shinose M, Kikuchi H, Shiba T, Sakaki Y, Hattori M, Omura S: Complete genome sequence and comparative analysis of the industrial microorganism Streptomyces avermitilis. Nat Biotechnol 2003, 21(5):526-531.

25. Oliynyk M, Samborskyy M, Lester JB, Mironenko T, Scott N, Dickens S, Haydock SF, Leadlay PF: Complete genome sequence of the erythromycin-producing bacterium Saccharopolyspora erythraea NRRL23338. Nat Biotechnol 2007, 25(4):447-453.

26. Ohnishi Y, Ishikawa J, Hara H, Suzuki H, Ikenoya M, Ikeda H, Yamashita A, Hattori M, Horinouchi S: Genome sequence of the streptomycinproducing microorganism Streptomyces griseus IFO 13350. J Bacterio/ 2008, 190(11):4050-4060.

27. Zhao W, Zhong Y, Yuan H, Wang J, Zheng H, Wang Y, Cen X, Xu F, Bai J, Han $X$, et al: Complete genome sequence of the rifamycin SV-producing Amycolatopsis mediterranei U32 revealed its genetic characteristics in phylogeny and metabolism. Cell Res 2010, 20(10):1096-1108.

28. Rokem JS, Lantz AE, Nielsen J: Systems biology of antibiotic production by microorganisms. Nat Prod Rep 2007, 24(6):1262-1287.

29. Wang Y, Chu J, Zhuang Y, Xia J, Zhang S: Industrial bioprocess control and optimization in the context of systems biotechnology. Biotechnol Adv 2009, 27(6):989-995.

30. Bentley SD, Brown S, Murphy LD, Harris DE, Quail MA, Parkhill J, Barrell BG, McCormick JR, Santamaria RI, Losick R, et al: SCP1, a 356,023 bp linear plasmid adapted to the ecology and developmental biology of its host, Streptomyces coelicolor A3(2). Mol Microbiol 2004, 51(6):1615-1628.

31. Jakimowicz D, Majka J, Messer W, Speck C, Fernandez M, Martin MC, Sanchez J, Schauwecker F, Keller U, Schrempf H, et al: Structural elements of the Streptomyces oriC region and their interactions with the DnaA protein. Microbiology 1998, 144(Pt 5):1281-1290.

32. Horvath $P$, Barrangou R: CRISPR/Cas, the immune system of bacteria and archaea. Science 2010, 327(5962):167-170.

33. Uchiyama I: MBGD: a platform for microbial comparative genomics based on the automated construction of orthologous groups. Nucleic Acids Res 2007, 35(Database issue):D343-D346. 
34. Capstick DS, Willey JM, Buttner MJ, Elliot MA: SapB and the chaplins: connections between morphogenetic proteins in Streptomyces coelicolor. Mol Microbiol 2007, 64(3):602-613

35. San Paolo S, Huang J, Cohen SN, Thompson CJ: Rag genes: novel components of the RamR regulon that trigger morphological differentiation in Streptomyces coelicolor. Mol Microbiol 2006, 61(5):1167-1186.

36. Wang J, Yu Y, Tang K, Liu W, He X, Huang X, Deng Z: Identification and analysis of the biosynthetic gene cluster encoding the thiopeptide antibiotic cyclothiazomycin in Streptomyces hygroscopicus 10-22. Appl Environ Microbiol 2010, 76(7):2335-2344.

37. Olano C, Lombo F, Mendez C, Salas JA: Improving production of bioactive secondary metabolites in actinomycetes by metabolic engineering. Metab Eng 2008, 10(5):281-292.

38. Fernandez Martinez $L$, Bishop A, Parkes L, Del Sol R, Salerno P, Sevcikova B, Mazurakova V, Kormanec J, Dyson P: Osmoregulation in Streptomyces coelicolor: modulation of SigB activity by OsaC. Mol Microbiol 2009, 71(5):1250-1262.

39. Willey JM, Gaskell AA: Morphogenetic signaling molecules of the Streptomycetes. Chem Rev 2011, 111(1):174-187.

40. Wray LV Jr, Atkinson MR, Fisher SH: Identification and cloning of the $g \ln R$ locus, which is required for transcription of the $g \ln A$ gene in Streptomyces coelicolor A3(2). J Bacteriol 1991, 173(22):7351-7360.

41. Choulet F, Aigle B, Gallois A, Mangenot S, Gerbaud C, Truong C, Francou FX, Fourrier C, Guerineau M, Decaris B, et al: Evolution of the terminal regions of the Streptomyces linear chromosome. Mol Biol Evol 2006, 23(12):2361-2369.

42. Komatsu M, Uchiyama T, Omura S, Cane DE, Ikeda H: Genome-minimized Streptomyces host for the heterologous expression of secondary metabolism. Proc Natl Acad Sci USA 2010, 107(6):2646-2651.

43. Chen W, He F, Zhang X, Chen Z, Wen Y, Li J: Chromosomal instability in Streptomyces avermitilis: major deletion in the central region and stable circularized chromosome. BMC Microbiol 2010, 10:198.

44. Sola-Landa A, Moura RS, Martin JF: The two-component PhoR-PhoP system controls both primary metabolism and secondary metabolite biosynthesis in Streptomyces lividans. Proc Natl Acad Sci USA 2003, 100(10):6133-6138.

45. Lee EJ, Karoonuthaisiri N, Kim HS, Park JH, Cha CJ, Kao CM, Roe JH: A master regulator sigma $B$ governs osmotic and oxidative response as well as differentiation via a network of sigma factors in Streptomyces coelicolor. Mol Microbiol 2005, 57(5):1252-1264.

46. Lian W, Jayapal KP, Charaniya S, Mehra S, Glod F, Kyung YS, Sherman DH, Hu WS: Genome-wide transcriptome analysis reveals that a pleiotropic antibiotic regulator, AfsS, modulates nutritional stress response in Streptomyces coelicolor A3(2). BMC Genomics 2008, 9:56.

47. Stein D, Cohen SN: A cloned regulatory gene of Streptomyces lividans can suppress the pigment deficiency phenotype of different developmental mutants. J Bacteriol 1989, 171(4):2258-2261.

48. Narva KE, Feitelson JS: Nucleotide sequence and transcriptional analysis of the redD locus of Streptomyces coelicolor A3(2). J Bacteriol 1990, 172(1):326-333.

49. Yeats C, Bentley S, Bateman A: New knowledge from old: in silico discovery of novel protein domains in Streptomyces coelicolor. BMC Microbiol 2003, 3:3.

50. Margulies M, Egholm M, Altman WE, Attiya S, Bader JS, Bemben LA, Berka J, Braverman MS, Chen YJ, Chen Z, et al: Genome sequencing in microfabricated high-density picolitre reactors. Nature 2005, 437(7057):376-380.

51. Delcher AL, Harmon D, Kasif S, White O, Salzberg SL: Improved microbial gene identification with GLIMMER. Nucleic Acids Res 1999, 27(23):4636-4641.

52. Guo FB, Ou HY, Zhang CT: ZCURVE: a new system for recognizing protein-coding genes in bacterial and archaeal genomes. Nucleic Acids Res 2003, 31(6):1780-1789.

53. Lowe TM, Eddy SR: tRNAscan-SE: a program for improved detection of transfer RNA genes in genomic sequence. Nucleic Acids Res 1997, 25(5):955-964.

54. Laslett D, Canback B: ARAGORN, a program to detect tRNA genes and tmRNA genes in nucleotide sequences. Nucleic Acids Res 2004 32(1):11-16

55. Kurtz S, Phillippy A, Delcher AL, Smoot M, Shumway M, Antonescu C, Salzberg SL: Versatile and open software for comparing large genomes. Genome Biol 2004, 5(2):R12.
56. Grissa I, Vergnaud G, Pourcel C: CRISPRFinder: a web tool to identify clustered regularly interspaced short palindromic repeats. Nucleic Acids Res 2007, 35(Web Server issue):W52-W57.

57. He Y, Wang Z, Bai L, Liang J, Zhou X, Deng Z: Two pHZ1358-derivative vectors for efficient gene knockout in Streptomyces. J Microbiol Biotechnol 2010, 20(4):678-682.

58. Gust B, Challis GL, Fowler K, Kieser T, Chater KF: PCR-targeted Streptomyces gene replacement identifies a protein domain needed for biosynthesis of the sesquiterpene soil odor geosmin. Proc Natl Acad Sci USA 2003, 100(4):1541-1546.

doi:10.1186/1471-2164-13-337

Cite this article as: Wu et al:: Genomic and transcriptomic insights into the thermo-regulated biosynthesis of validamycin in Streptomyces hygroscopicus 5008. BMC Genomics 2012 13:337.

\section{Submit your next manuscript to BioMed Central and take full advantage of:}

- Convenient online submission

- Thorough peer review

- No space constraints or color figure charges

- Immediate publication on acceptance

- Inclusion in PubMed, CAS, Scopus and Google Scholar

- Research which is freely available for redistribution 